\title{
Epikeratophakia: Clinical Results and Experimental Development
}

\author{
CHAD K. ROSTRON \\ Leicester
}

\begin{abstract}
Summary
The clinical course and visual, refractive, and keratometric results of a consecutive series of epikeratophakia procedures carried out by the author are presented. Indications for the procedure included keratoconus and adult and paediatric aphakia. Follow up time ranged from two to fourteen months. The first five patients operated on received commercially obtained cryolathed lenticules. The final three cases received lenticules which were lathed by the author at room temperature using a recently developed technique.
\end{abstract}

Epikeratophakia was devised by Werblin in 1979 and subsequently developed by Kaufman and McDonald. In 1984 a multicentre trial was commenced using lenticules lathed commercially by American Medical Optics (now Allergan Medical Optics-AMO). The procedure was initially devised for the refractive correction of adult and paediatric aphakia and subsequently modified to treat myopia and phakic hypermetropia. Epikeratophakia with plano powered lenticules was developed to treat keratoconus, and such lathed tissue may also be used for lamellar keratoplasty. Clinical experience with epikeratophakia in the United States is now extensive and recent publications report favourable clinical results. ${ }^{1,2.3 .4}$

In 1982 Maguen et al. ${ }^{5}$ reported a new technique for lathing corneal tissue at room temperature. This was achieved by a preliminary lyophilisation (freeze drying) of the tissue to render it suitable for lathing. The corneal button was held on the lathe by allowing it to become adherent to a polymethyl methacrylate (PMMA) base using a 'biological adhe- sive' containing sucrose. Maguen et al. published the results of a series of experimental keratophakia procedures in cats with good results, and suggested that the technique could be applied to the production of lenticules for epikeratophakia. ${ }^{6}$ More recently Rostron et al. have reported a modification of the technique of lathing at room temperature and used lenticules produced by this method to carry out experimental epikeratophakia.? Using this modified technique lenticules have been produced for clinical use and this paper reports the results of human epikeratophakia using tissue lathed at room temperature.

\section{Material and Methods}

The series of patients reported represent the author's first year of clinical experience with the procedure. The first five patients received lenticules obtained from AMO. These lenticules were ordered on the basis of an averaged keratometry reading and the refractive error, which was corrected to the corneal plane and rounded to the nearest half dioptre. The lenticules were prepared by cryolathing. 
The tissue was subsequently lyophilised and sent by airmail from the United States to this country. No details are available of the lathing parameters used or the technique of lyophilisation.

The final three cases received lenticules prepared by the author, using a technique of lathing tissue at room temperature. Tissue for these patients was prepared in the following way:

Donor eyes were enucleated and the corneo-scleral rims preserved in McCarey-Kaufman (MK) medium at $4{ }^{\circ} \mathrm{C}$. Donors were selected according to the same criteria applied for penetrating keratoplasty, and all donors were screened for serum antibodies to HIV. Tissues were used for epikeratophakia only if it was deemed unsuitable for penetrating keratoplasty due to known or presumed poor endothelial cell count from prolonged death to enucleation time, or prolonged storage. After storage for up to four days the corneas were removed from the MK medium. The corneal epithelium was stripped with a scalpel blade and the endothelium and Descemet's membrane were also removed. The corneoscleral button was then placed in cryopreservative solution for thirty minutes. This solution was prepared in our pharmacy under sterile conditions from Dextran 70, dextrose and dimethyl sulphoxide (DMSO). Corneas were frozen and preserved in this solution in liquid nitrogen for periods ranging from one to four months. When removed from liquid nitrogen the corneas were allowed to thaw and were cut to an appropriate diameter on a corneal punch. The corneal button was then placed on a PMMA base which had a concavity of $8 \mathrm{~mm}$ radius cut into its surface. The button was desiccated on the base at $4{ }^{\circ} \mathrm{C}$ for twenty-four hours. This allowed sufficient drying of the cornea to make it adherent to the underlying PMMA base and to allow it to be lathed at room temperature. Lathing was carried out on a cryolathe with the cryo circuitry switched off. The lathing parameters used were based on the theoretical model proposed by Werblin et al. ${ }^{8}$ Following lathing, the PMMA bases were removed from the cryolathe and the corneas soaked in Dextran 70 for five minutes to allow them to be removed atraumatically from the base. The corneas were then replaced on the PMMA bases and desiccated for 48 hours at $4{ }^{\circ} \mathrm{C}$. Under these circumstances the desiccated lenticules did not become adherent to the base because of the absence of biological adhesive. The lenticules were then placed in a vial on an Edwards' model $12 \mathrm{~K}$ freeze dryer and lyophilised at $-50^{\circ} \mathrm{C}, 3 \mathrm{mbar}$ for 24 hours. The vials were sealed whilst still under vacuum and the lenticules were maintained in this state at room temperature until used for surgery.

\section{Surgical Technique}

General anaesthesia was used in all cases. Topical antibiotics were used pre-operatively. At surgery, topical cocaine was applied to the patient's corneal epithelium which was then stripped leaving a residual $1 \mathrm{~mm}$ rim at the limbus. A partial thickness trephine cut was made; $7 \mathrm{~mm}$ diameter for the aphakic patients and $9 \mathrm{~mm}$ for the keratoconus patients. A wedge of tissue on the inner aspect of the trephine cut was resected with Vannas' scissors. A peripheral lamellar split was made at the base of the trephine cut to accommodate the lenticule wing zone. Lenticules were rehydrated for 20 minutes in normal saline with gentamicin 100 microgm per ml. They were sutured in place with 16 to 24 interrupted 10/0 Dermalon sutures. Subconjunctival methyl prednisolone acetate $20 \mathrm{mg}$ and gentamicin $20 \mathrm{mg}$ were given and a high water content bandage soft contact lens applied. Post-operatively the bandage lens was worn until the graft had re-epithelialised. Sutures were removed at 1 to 2 months for the aphakic patients and at 3 months for the keratoconus patients.

\section{Results}

Table I shows the background data for the patients in this series.

Figure 1 shows the unaided acuities before and after surgery. Acuities are recorded for only seven cases as in one case no measurements were available due to the patient's severe mental retardation (case 6).

Figure 2 shows best corrected acuity before and after surgery. Pre-operatively all patients were intolerant of the glasses or contact lenses used to measure this 'best corrected acuity', 
Table I

\begin{tabular}{lllcrc}
\hline Case & Indication & $\begin{array}{l}\text { Associated } \\
\text { conditions }\end{array}$ & $\begin{array}{c}\text { Follow up } \\
\text { time (mths) }\end{array}$ & Age & $\begin{array}{c}\text { Lenticule } \\
\text { source }\end{array}$ \\
\hline $1(\mathrm{l})$ & Adult aphakia & Uveitis optic atrophy & 14 & 55 & USA \\
$1(\mathrm{r})$ & Adult aphakia & Cataract uveitis & 2 & 56 & UK \\
2 & Adult aphakia & Previous uveitis & 13 & 73 & USA \\
3 & Adult aphakia & Penetrating eye injury & 8 & 20 & USA \\
4 & Paediatric aphakia & Previous uveitis & 7 & 6 & USA \\
5 & 'Unilateral' keratoconus & Minimal axial scarring & 5 & 29 & USA \\
6 & Bilateral keratoconus & Down's Syndrome hydrops & 2 & 10 & UK \\
7 & Limbal dermoid & Amblyopia astigmatism & 2 & 26 & UK \\
\hline
\end{tabular}

but this was not necessarily the case postoperatively.

Table II shows the details of pre- and postoperative visual acuities, refraction and keratometry.

Because of the heterogeneity of both the patients' conditions and the indications for surgery further analysis will consider the patients in sub-groups according to the indication for surgery.

\section{Adult Aphakia}

\section{Patient 1}

This patient suffers from multiple sclerosis and bilateral recurrent anterior uveitis. At the time of initial surgery she was unilaterally aphakic and could not tolerate her contact lens. She was unsuitable for intraocular lens implantation because of her uveitis, so epikeratophakia was carried out. Despite cover with pre-operative systemic steroids, the surgery provoked a recurrence of her uveitis, with hyopopyon formation on the third post-operative day. This cleared with additional treatment of intensive topical steroids. Following suture removal at one month post-operatively an interface opacity appeared beneath the site of one of the suture tracks, apparently due to proliferation of the corneal epithelium caught at the graft/host interface. However, this regressed spontaneously over the following 6 weeks. Best corrected acuity was only $6 / 18$ post-operatively due to preretinal gliosis at the macula and a degree of optic atrophy. This patient subsequently underwent epikeratophakia in her second eye. As she had undergone previous refractive correction of her unilateral aphakia, refractive correction of her second eye was necessary when this eye subsequently required cataract extraction. Because contact lens intolerance was anticipated, and intraocular lens implantation contraindicated due to chronic uveitis, epikeratophakia surgery was considered the treatment of choice. To save her undergoing two separate operations, epikeratophakia was carried out at the same time as the cataract extraction. Post-operatively there was again a rebound flare up of her uveitis with a small hypo-
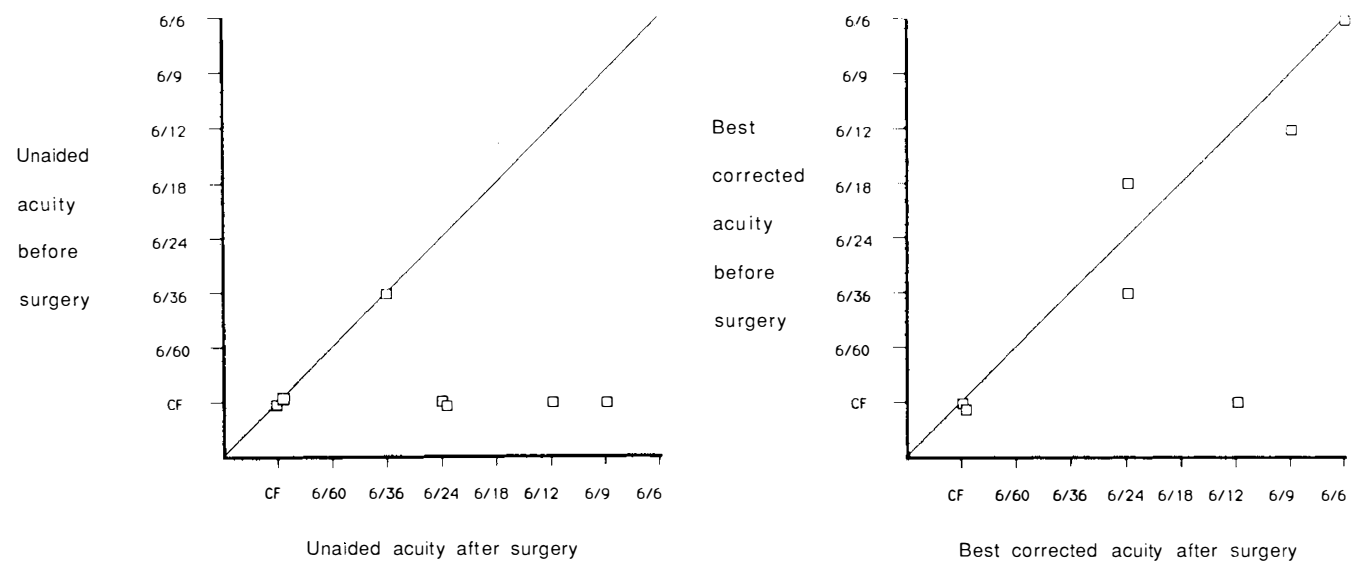

Fig. 1

Fig. 2 


\begin{tabular}{|c|c|c|c|c|c|c|c|c|}
\hline \multirow[b]{2}{*}{ Case } & \multicolumn{4}{|c|}{ Pre-operative } & \multicolumn{4}{|c|}{ Post-operative } \\
\hline & $\begin{array}{l}\text { Vision } \\
\text { unaided }\end{array}$ & $\begin{array}{l}\text { Vision } \\
\text { with } \\
\text { glasses }\end{array}$ & Refraction & Keratometry & $\begin{array}{c}\text { Vision } \\
\text { unaided }\end{array}$ & $\begin{array}{c}\text { Vision } \\
\text { with } \\
\text { glasses }\end{array}$ & Refraction & Keratometry \\
\hline $1(\mathrm{l})$ & $\mathrm{CF}$ & $6 / 18$ & +12 Sph. & $\begin{array}{l}7.70 @ 90^{\circ} \\
7.67 @ 180^{\circ}\end{array}$ & $6 / 24$ & $6 / 24$ & $\begin{array}{l}\text { plano } \\
+2.0 \times 10^{\circ}\end{array}$ & $\begin{array}{l}6.10 @ 90^{\circ} \\
6.42 @ 180^{\circ}\end{array}$ \\
\hline $1(\mathrm{r})$ & $\mathrm{CF}$ & $\mathrm{CF}$ & & $\begin{array}{l}7.68 @ 90^{\circ} \\
7.70 @ 180^{\circ}\end{array}$ & $\begin{array}{l}\text { CF } \\
\text { N12 }\end{array}$ & $\mathrm{CF}$ & $\begin{array}{l}-6.0 \\
+0.5 \times 90^{\circ}\end{array}$ & $\begin{array}{l}5.64 @ 90^{\circ} \\
5.78 @ 180^{\circ}\end{array}$ \\
\hline 2 & $\mathrm{CF}$ & $6 / 12$ & $\begin{array}{l}+10.5 \\
+1.5 \times 145^{\circ}\end{array}$ & $\begin{array}{l}7.39 @ 55^{\circ} \\
7.35 @ 145^{\circ}\end{array}$ & $6 / 24$ & $6 / 9$ & $\begin{array}{l}+4.0 \\
+1.5 \times 45^{\circ}\end{array}$ & $\begin{array}{l}6.50 @ 55^{\circ} \\
6.58 @ 145^{\circ}\end{array}$ \\
\hline 3 & $\mathrm{CF}$ & $6 / 6$ & $\begin{array}{l}+10.5 \\
+2.0 \times 90^{\circ}\end{array}$ & $\begin{array}{l}7.86 @ 90^{\circ} \\
8.55 @ 180^{\circ}\end{array}$ & $6 / 9$ & $6 / 6$ & $\begin{array}{l}-1.5 \\
+2.0 \times 70^{\circ}\end{array}$ & $\begin{array}{l}6.11 @ 90^{\circ} \\
6.63 @ 180^{\circ}\end{array}$ \\
\hline 4 & $\mathrm{CF}$ & $1 / 60$ & +15 & $\begin{array}{l}7.88 @ 90^{\circ} \\
7.88 @ 180^{\circ}\end{array}$ & $\begin{array}{l}2 / 60 \\
\mathrm{~N} 48\end{array}$ & $2 / 60$ & & 6.20approx \\
\hline 5 & $\mathrm{CF}$ & $\mathrm{CF}$ & & & $6 / 12$ & $6 / 12$ & & $\begin{array}{l}7.40 @ 90^{\circ} \\
7.20 @ 180^{\circ}\end{array}$ \\
\hline 7 & $6 / 36$ & & & & $6 / 36$ & $6 / 24$ & $\begin{array}{l}+1.0 \\
+5.0 \times 125^{\circ}\end{array}$ & \\
\hline
\end{tabular}

pyon formation on the third post-operative day. This was assumed to be sterile and responded well to topical and systemic steroids. Although this case has only a short follow up time, the latest postoperative refraction shows over correction in the second eye, and, as in the other eye, corrected visual acuity is poor due to optic atrophy and preretinal gliosis of the macula.

\section{Patient 2}

This patient had undergone intracapsular cataract extraction with broad iridectomy in an eye which had showed signs of previous uveitis. The patient refused to consider wearing a contact lens, but was unhappy with the blurred vision from her uncorrected unilateral aphakia. Following epikeratophakia, her post-operative course was complicated by a persistent epitheliopathy over the apex of the graft. However, the epithelium stabilised after three months. At six months post-operatively the residual uncorrected refractive error in the operated eye was $+5.75 \mathrm{D}$ spherical equivalent which still left her with a total of $+8.5 \mathrm{D}$ of anisometropia. Thus with a spectacle correction for her residual refractive error she experienced constant aniseikonic diplopia. To overcome this she subsequently underwent cataract extraction with intra-ocular lens implantation in her second eye, with intentional undercorrection to reduce her anisometropia to a tolerable degree.

\section{Patient 3}

This patient had suffered paracentral corneal lac- eration from the branch of a tree. The wound was complicated by formation of a cataract which was aspirated shortly after the injury. He had attempted contact lens wear over a period of several years but had been intolerant. The epikeratophakia surgery and follow up were uncomplicated and achieved a satisfactory refractive result. He now has good vision (6/9) with binocular function for near and distance, and an unaided stereo acuity of 140 secs of arc at 16 inches.

\section{Paediatric Aphakia}

\section{Patient 4}

This child presented at the age of 4 years with visual acuity 6/9 right and 6/6 left (Sheridan Gardner) and with acute anterior uveitis in his right eye. Investigation had shown no abnormality apart from positive titre to toxacara. He was treated with topical and systemic steroids and six months later in November 1984, visual acuity in the right eye had deteriorated to counting fingers and there was considerable vitreous haze. He continued on topical steroids in low dosage and by April 1986 had developed a mature cataract in his right eye. Right extracapsular cataract extraction was carried out in June 1986 and epikeratophakia in November 1986. Sutures were removed under general anaesthesia at 2 weeks post-operatively and the graft was clear with good epithelial cover at that time. Two weeks later there was extensive secondary epithelial break down over the graft, producing much pain and photophobia. Various bandage contact lenses and 
patching were tried unsuccessfully. Due to the persistent epithelial defect tarsorraphy was carried out under general anaesthesia in January 1987. When the tarsorraphy was opened three weeks later the graft epithelium had stabilised but there was residual graft surface irregularity and subepithelial scarring at the site of the previous epithelial defect. $\mathrm{He}$ is currently undergoing occlusion therapy, but with limited compliance. Accurate post-operative keratometry and refraction measurements have not been possible due to the child's poor co-operation.

\section{Keratoconus}

\section{Patient 5}

This patient had a 6-year history of 'unilateral' keratoconus and at presentation was felt to have too steep a cone to be successfully fitted with a contact lens. Pre-operative acuity in this eye was counting fingers unaided and with glasses, but improved to $6 / 24$ with pinhole. The post-operative course was complicated by a transient secondary epithelial breakdown over the centre of the graft associated with suture loosening. However, this resolved by wearing a bandage contact lens. Final visual acuity was $6 / 12$ unaided and the patient continues with spectacle correction for his other eye, which corrects to $6 / 6$.

\section{Patient 6}

This child with Down's Syndrome and severe mental retardation also suffered from bilateral keratoconus and congenital cataracts. Both cataracts had been needled on several occasions during infancy. She was considered unsuitable for penetrating keratoplasty due to her poor co-operation and tendency to rub her eyes. This appeared to be associated with progression of her keratoconus, and unfortunately while awaiting surgery she developed acute corneal hydrops in the eye upon which it was planned to operate. At the time of surgery the cornea was found to be considerably ectatic, oedematous, and had widespread corneal opacification. To simplify post-operative management, bandage contact lens wear was not attempted but tarsorraphy was carried out at the time of surgery. When the tarsorraphy was opened at 3 weeks the graft was found to have epithelialised satisfactorily. The epithelium has remained stable and sutures were removed at three months. Due to the child's severe retardation, measurement of visual acuity and keratometry were not possible.

\section{Patch Grafting}

\section{Patient 7}

This patient had two corneo-scleral dermoids in her left eye. One of these had been removed when she was 6 months old but the other had been left, as although it encroached on her cornea to a greater extent, it was partly hidden by the upper lid. The visual axis of the eye was clear, but the eye was amblyopic from a high degree of oblique astigmatism. The patient sought removal of the dermoid for cosmetic reasons and lyophilised tissue which had been lathed to a uniform thickness of $0.45 \mathrm{~mm}$ was used as a lamellar graft to replace the corneal defect following excision of the dermoid. Re-epithelialisation over the inner edge of the graft was slow due to unevenness of the graft-host interface. However, the epithelium eventually healed at 6 weeks post-operatively. Removal of a loose suture at one week post-operatively was complicated by haemorrhage into the graft/host interface, but this cleared over the ensuing weeks.

\section{Discussion}

Whilst the small size of this series precludes statistical analysis of the results, consideration of individual cases demonstrates several important aspects of this procedure. The large series of cases reported from the multicentre epikeratophakia trial in the United States give a good indication of the level of success that can be expected with this operation. The results of treatment of adult and paediatric aphakia are certainly encouraging, ${ }^{1.2}$ and the procedure can offer a realistic alternative to those for whom secondary intraocular lens implantation would be the only other option. ${ }^{9}$

\section{Adult Aphakia Correction}

Two of the cases in this series were corrected to within $1.0 \mathrm{D}$ of emmetropia, and the result in case 3 with restoration of binocular function is an example of epikeratophakia at its best. However, case number 2 showed a marked degree of under correction, changing from $+11 \mathrm{D}$ pre-operatively to $+5.75 \mathrm{D}$ post-operatively; less than 50 per cent of the desired change. A degree of inaccuracy in aphakic correction can sometimes be tolerated, as the patient may already wear spectacles, so the residual ametropia can be corrected with glasses. However, in this case, the under correction was so marked that the procedure completely failed to reduce the anisometropia to a tolerable degree. Because there is no way of checking a lenticule's power prior to its application, and because the lathing para- 
meters used for this commercially obtained lenticule were unknown, it is only possible to conjecture as to the cause of this under correction. Whilst the lenticule may have been inaccurately cut in the first place, it seems more likely that the under correction obtained in this case was due both to over tight suture technique and to the effect of leaving sutures in place for too long. In this patient it was noted in the early post-operative phase that there was significant folding in Descemet's membrane largely confined to the area beneath the lenticule. This may have been due to relative corneal decompensation, but it might alternatively indicate that the suture tension was too great, which could have caused flattening of the central cornea with reduction of the refractive effect achieved by the lenticule. The possibility of modifying the result by trephining down through the wing zone of the lenticule to release the wound tension was considered. However, in this case it was felt inappropriate to subject the patient to another operative procedure with an unpredictable result. Instead it was decided that a better way to eliminate the anisometropia would be to proceed with cataract extraction in her other eye, which was considered suitable for intra-ocular lens implantation since it showed no signs of previous uveitis. She now has binocularity restored with a low hypermetropic spectacle correction for both eyes.

Conversely, in the second eye of case 1, there was an over correction of 5.75 D. In this instance there was no clinical evidence of the sutures being too tight, and the sutures were removed early, so this probably represents a situation where surgically induced under correction was minimised. As this case underwent combined cataract extraction and epikeratophakia, the lenticule power was predicted by ocular biometry and the use of the SRK formula corrected to the corneal plane, and this might account for some error in the final refractive result. It is also possible that the over correction was due to the lathing parameters being incorrect. Lathing of this lenticule was carried out according to the theoretical model described by Werblin et al. ${ }^{8}$

Werblin found that experimental epikeratophakia in monkeys produced refractive results which deviated significantly from the theoretical prediction, but that by changing the surgical technique and lenticule design results could be obtained that approximated more closely to the theoretical model. ${ }^{10}$ In early trials of epikeratophakia in humans no attempt was made to achieve specific refractive corrections and lenticules were only designated as 'low plus' and 'high plus'. ${ }^{11}$ More recent reports ${ }^{1,2}$ have documented the clinical outcome of over 800 cases but the lathing parameters used were not specified. Nor has the relationship between the theoretically described lathing parameters and those actually used in these studies been stated.

In this series the refractive results obtained in case 1 (1) and case 3 were quite reasonable, but cases $1(r)$ and 2 showed quite wide deviation from the predicted result. It appears that factors such as the surgical technique used, and in particular the suture tightness, can have a profound effect on the refractive result obtained. For this reason further research is needed to find ways to cut down the possibility of inducing such errors. Development of a sutureless technique could both improve the accuracy and diminish the operating time for this procedure.

\section{Paediatric Aphakia Correction}

The use of epikeratophakia in paediatric aphakia with contact lens intolerance has achieved some very successful results. ${ }^{2}$ Inevitably a proportion of patients fail to achieve good acuities due to poor compliance with occlusion therapy, but it is not always possible to predict the degree of compliance before embarking on treatment. The child in this series suffered from a secondary epithelial breakdown on the graft, and whilst this did not necessitate graft removal, it left a degree of scarring when it healed. It is difficult to apportion how much the final visual outcome will be affected by the scarring, but the amblyopia would appear to be the major detrimental factor at this point of follow up. In reported series of paediatric cases around 10 per cent of grafts need removal, most commonly from problems with epithelial defects. However, a proportion of these cases can be successfully re-grafted. ${ }^{2}$ 


\section{Keratoconus and Patch Grafting}

The treatment of keratoconus by onlay lamellar epikeratoplasty now offers an alternative in a situation where previously the only surgical option available was penetrating keratoplasty. Early reports of the technique have been favourable and the results in this study also support these findings. ${ }^{3}$ One of the main benefits of epikeratoplasty is its lack of problems with rejection and the results of epikeratophakia can only be fairly compared with those of penetrating keratoplasty when longer follow up times are available.

Plano powered lenticules can readily be prepared using the room temperature technique, and when lyophilised this tissue is convenient for use both for the treatment of keratoconus and, as in case 7 , for patch grafting. The storage of tissue in a lyophilised state is one of the factors that has done much to popularise epikeratophakia as a procedure. Techniques such as BKS $1000^{12}$ and excimer laser $^{13}$ can be used to cut lenticules for epikeratophakia without causing keratocyte or epithelial cell death, and thus provide a living' lenticule. However, this means that the lenticule must be prepared by the surgeon, or rapidly transported in culture medium to the centre where it is to be used. The preparation of 'living' tissue is not necessarily an advantage that outweighs the convenience of having tissue in a lyophilised state. Whether any of these new techniques will prove able to achieve greater accuracy in refractive correction will only be established by further experimental evaluation and clinical trials.

I should like to thank Professor A. R. Rosenthal, Mr. J. H. Sandford-Smith, Mr. A. R. Fielder, Mr. J. Cappin and Mr. D. J. Austin for allowing me to report on their patients, Mr. D. Shaw for assistance with computing, and my wife for preparing the manuscript.

\section{References}

${ }^{1}$ McDonald MB, Kaufman HE, Aquavella JV et al.: The Nationwide study of epikeratophakia for aphakia in adults. Am J Ophthalmol 1987, 103: 358-65.

${ }^{2}$ Mogan KS, McDonald MC, Hiles DA et al.: The nationwide study of epikeratophakia for aphakia in children. Am J Ophthalmol 1987, 103: 366-74.

${ }^{3}$ McDonald MB, Kaufman HE, Durrie DS et al.: Epikeratophakia for keratoconus. The nationwide study. Arch Ophthalmol 1986, 104: 12941300.

${ }^{4}$ Busin M, Halliday BL, Arffa RC et al.: Precarved lyophilised tissue for lamellar keratoplasty in recurrent pterygium. Am J Ophthalmol 1986, 102: 222-7.

${ }^{5}$ Maguen E and Nesburn AB: A new technique for lathing lyophilised cornea for refractive keratoplasty. Arch Ophthalmol 1982, 100: 119-21.

${ }^{6}$ Maguen E, Pinhas S, Verity SM, Nesburn AB: Keratophakia with lyophilised cornea lathed at room temperature: new techniques and experimental surgical results. Ophthalmol Surg 1983, 14: 759_ 62.

${ }^{7}$ Rostron CK, Sandford-Smith JH, Morton DB: Experimental epikeratophakia using tissue lathed at room temperature. Br JOphthalmol (In press).

${ }^{8}$ Werblin TP and Klyce SD: Epikeratophakia: the surgical correction of aphakia. I. Lathing of corneal tissue. Curr Eye Res 1981, 1: 123-9.

${ }^{9}$ Durrie DS, Habrich DL, Dietze TR: Secondary intraocular lens implantation vs epikeratophakia for the treatment of aphakia. Am J Ophthalmol 1987, 103: 384-91.

${ }^{10}$ Werblin TP and Kaufman HE: Epikeratophakia: the surgical correction of aphakia. II. Preliminary results in a nonhuman primate model. Curr Eye Res 1981, 1: 131-7.

${ }^{11}$ Morgan KS, Arffa RC, Marvelli TL et al.: Five year follow-up of epikeratophakia in children. Ophthalmology 1986, 93: 423-32.

${ }^{12}$ Swinger CA, Krumeich J, Cassidy D: Planar lamellar refractive keratoplasty. J Ref Surg 1986, 2: 17-24.

${ }^{13}$ Lieurance RC, Patel AC, Lee Wan W et al.: Excimer laser cut lenticules for epikeratophakia. Am J Ophthalmol 1987, 103: 475-6. 